\title{
Factors Associated with Untreated Depression Among Type 2 Diabetic Patients at Halaba Kulito Hospital, South Ethiopia: A Cross-Sectional Study
}

This article was published in the following Dove Press journal: Diabetes, Metabolic Syndrome and Obesity: Targets and Therapy

\author{
Gedion Asnake Azeze $\mathbb{D}^{\prime}$ \\ Bulcha Guye Adema (D) ${ }^{2}$ \\ Getachew Asmare Adella ${ }^{3}$ \\ Birhanu Wondimeneh \\ Demissie $^{2}{ }^{2}$ \\ Mohammed Suleiman Obsa $\mathbb{D D}^{4}$ \\ 'Department of Midwifery, College of \\ Health Science and Medicine, Wolaita \\ Sodo University, Wolaita Sodo, Ethiopia; \\ ${ }^{2}$ Department of Pediatrics and Child \\ Health Nursing, College of Health \\ Science and Medicine, Wolaita Sodo \\ University, Wolaita Sodo, Ethiopia; \\ ${ }^{3}$ Reproductive Health and Nutrition \\ Department, School of Public Health, \\ College of Health Science and Medicine, \\ Wolaita Sodo University, Wolaita Sodo, \\ Ethiopia; ${ }^{4}$ Department of Anesthesia, \\ College of Health Science and Medicine, \\ Wolaita Sodo University, Wolaita Sodo, \\ Ethiopia
}

Background: Depressed type 2 diabetes mellitus patients (T2DM) show poorer compliance with treatment and self-care recommendations than non-depressed T2DM patients. This contributes to poor prognosis and accelerates diabetic-related complications including poor glucose regulation, diabetic retinopathy, neuropathy, nephropathy, and escalated healthcare expenditure.

Objective: This study aimed to determine the magnitude of untreated depression and associated factors among people living with T2DM at outpatient diabetic clinic in Halaba Kulito General Hospital, Southern Ethiopia.

Methods: Institution-based cross-sectional study was conducted from November 1 to December 15, 2019 at Halaba Kulito Hospital, Southern Ethiopia. We collected data by faceto-face interview with patient record review. A total of 418 type 2 diabetic patients were systematically selected and interviewed using a pretested structured questionnaire. We used a composite score of nine-items Patient Health Questionnaire (PHQ-9) to assess depression status. Descriptive statistics was used to summarize respondents' background characteristics. Logistic regression analysis was done to identify associated factors with the outcome variable. Levels of significance were set at $5 \%(\mathrm{P}<0.05)$.

Results: The finding depicted that 120 (29.3\% with 95\% Confidence interval $(\mathrm{CI})=25.0 \%$, $34.0 \%$ ) study participants satisfied diagnostic criteria for depression disorder. After controlling for confounding effect, we identified being hypertensive (Adjusted Odds Ratio (AOR) = 5.66; 95\% CI: 3.24, 9.86), having no child (AOR $=3.32$; 95\% CI: $1.88,5.86$ ), and poor glycemic control (AOR $=6.23 ; 95 \% \mathrm{CI}: 3.65,10.54)$ as risk factors for untreated depression among people with type 2 diabetes.

Conclusion: Findings of this study indicate that untreated depression among type 2 diabetic patients is high. Poor glycemic control, not having a child and having hypertension were among significantly associated factors with depression. These results suggest much need for interventions, including strong medication adherence and self-care activities such as exercise or healthful diet for optimal glycemic control.

Keywords: anxiety, depression, diabetes, Ethiopia

\section{Background}

Diabetes mellitus (DM), a leading endocrine disorder with growing public health concern globally, is characterized by elevated blood glucose level when the pancreas produces little or no insulin or variable degrees of cells' resistance to insulin or both. ${ }^{1}$ The burden of diabetes is rising and has been becoming among the few major public health challenges to the health services and economic development
Correspondence: Gedion Asnake Azeze Department of Midwifery, College of Health Science and Medicine, Wolaita Sodo University, PO Box 136, Wolaita Sodo, Ethiopia

Email dearged20II@gmail.com 
(Medical and treatment cost), particularly in developing countries including Ethiopia., ${ }^{2,3}$ Studies in Ethiopia showed visual disturbance, hypertension, neuropathy and nephropathy were the top four chronic complications diagnosed in DM patients. ${ }^{4}$ Despite this, a systematic review on prevalence and related acute and chronic complications shows insufficient priority given to diabetes and interventions to prevent acute and long-term complications are lacking in Ethiopia at a national level with the major focus of the country on combating infectious disease. ${ }^{5,6}$

Depression is a state of depressed mood, low energy and poor concentration, feelings of guilt or low self-worth, loss of interest or pleasure, disturbed sleep or appetite, and aversion to activity affecting a person's behavior and feelings, thoughts, and sense of wellbeing. ${ }^{7,8}$ It is the second leading cause of burden of disease, with around 340 million people of all ages suffering from depression globally. ${ }^{9-11}$

Though the two are separate entities and are by themselves major health problems in the world, the association between diabetes mellitus and depression is well established from a growing body of literature. Most notably, evidence shows that the relationship between depression and T2DM has been found to be bi-directional; $;^{9,12,13}$ the likelihood of depression in (T2DM) patients is approximately double that found in the overall population ${ }^{13}$ whereas depressed patients have $60 \%$ increased risk of developing type 2 diabetes. ${ }^{1,14}$

Depressed type 2 diabetic patients show poorer compliance with treatment and self-care recommendations than non-depressed T2DM patients. This contributes to poor prognosis and accelerates diabetic-related complications including poor glucose regulation, diabetic retinopathy, neuropathy, nephropathy, and escalated healthcare expenditure. ${ }^{12,14-16}$ Despite this, depression in diabetes is recognized and treated in only about one-third of cases. ${ }^{17}$

According to the International Diabetes Federation (IDF2014), an estimated 4.9 million people in Ethiopia aged 20 to 79 years are suffering from diabetes. ${ }^{18}$ Although there are not many, studies from some parts of Ethiopia assessed the prevalence and risk factors associated with depression among people with diabetes. An institution-based crosssectional study conducted in Gondar town, Northwest Ethiopia, for instance, discovered $15.4 \%$ prevalence of depression among diabetic patients. ${ }^{9}$ While from a study conducted in Oromia region, Western Ethiopia, disproportionately high (47\%) prevalence of depression among T2DM patients was documented with risk factors for increased prevalence being female, lack of school education, current use of alcohol, having chronic complication of DM, more than five years of being diabetic patient and having other additional chronic illness. ${ }^{19}$ Although depression is common, it is often ignored, undiagnosed and untreated in DM patients. ${ }^{20}$ In general, a number of studies showed that the presence of untreated depression in patients with DM is associated with the burden of complications, financial stress, poor overall health status, poor glycemic control, decreased the quality of life and increases mortality. ${ }^{6}$

Given one of the top five countries with the highest number of people affected by DM in sub-Saharan Africa (SSA) and depression, contributing the highest share of burden compared to other forms of mental disorders, ${ }^{9}$ there is limited information regarding the status of depression specifically among T2DM patients in Ethiopia. Hence, the purpose of this study was to determine the magnitude of untreated depression and associated factors among people living with T2DM at an outpatient diabetic clinic in Halaba Kulito General Hospital, Southern Ethiopia. Identifying the factors may help in developing intervention strategies explicitly targeting the prevention of depression among T2DM patients.

\section{Methods and Materials Study Design and Period}

We conducted an institution-based cross-sectional study at Halaba Kulito primary hospital. The study was conducted from November 1to December 15, 2019.

\section{Study Setting}

Ethiopia is located in the Horn of Africa and is the second most populated country in sub-Saharan Africa, with almost 105 million inhabitants. ${ }^{21}$ Halaba Kulito town, the administrative center of Halaba special district, is found in Hadiya zone, Southern Nations, Nationalities and Peoples' Region (SNNPR), Ethiopia. The town is located $245 \mathrm{~km}$ south from Addis Ababa, the capital of Ethiopia, and $90 \mathrm{~km}$ from Hawassa, the capital city of SNNPR. Estimated total population residing in the town is 39,507 people $(49 \%(19,358)$ males and $51 \%(20,149)$ females $)$. There is one health center and one primary hospital in the town. The hospital provides service for more than 100,000 people in the catchment area. It has one emergency, three outpatient departments, antiretroviral treatment care, maternal and child health care, ophthalmology and 
dentistry departments and four wards; gynecology and obstetrics, pediatrics, medical and surgical wards.

\section{Source and Study Participants}

The source population was all diabetic patients who have a medical follow-up at Halaba Kulito primary hospital, and diabetic patients who had follow-up at this hospital during the study period were the study population. Those patients aged 18 years and above with the diagnosis of diabetes, obtained from patient's medical records, for at least six months were included in the study while patients with a history of mental illness and head injury were excluded. Further, we excluded patients already on antidepressants because pharmacological treatment with antidepressants for psychiatric disorders can help patients achieve better glycemic control and have been shown to prevent depression in patients with diabetes ${ }^{12}$ and could have therefore underestimated its prevalence.

\section{Sample Size Determination and Sampling Technique}

We calculated sample size using a single population proportion formula by using assumptions of $95 \%$ confidence level and 5\% margins of error. Also, we used $44.7 \%$ prevalence of diabetic depression among type 2 diabetic outpatients in Black Lion General Specialized Hospital, Addis Ababa, Ethiopia. ${ }^{22}$ Considering 10\% non-response rate, the total sample size became 418 .

By taking three months of average client flow, monthly patient flow registered in the diabetic clinic was 458 . We used systematic random sampling technique to recruit every $\mathrm{k}^{\text {th }}$ eligible respondent which gives sampling interval of two over two months data collection period and sequence of client flow at the diabetic outpatient clinic was used as a sampling frame. Lottery method was used to select the first participant then every subsequent participant was selected by skipping two clients until the required sample size was reached.

\section{Study Instrument}

Clinical information includes diagnosis of diabetes, fasting plasma glucose and medication history; complications and comorbidities including hypertension, retinopathy, nephropathy and neuropathy were obtained from medical records of patients. Patients with established type 2 diabetes mellitus were evaluated for depression by interviewer administered nine-item Patient Health Questionnaire (PHQ-9). The PHQ-9 diagnosis has a high agreement with major depression diagnosis based on structured interviews with $78 \%$ sensitivity and $98 \%$ specificity. $^{23}$ It was an easy depression screening tool which was a brief questionnaire that scores each of 9 DSM-IV criteria for depression as " 0 " (not at all) to "3" (nearly every day). PHQ-9 scores of $5,10,15$, and 20 represent mild, moderate, moderately severe and severe depression, respectively.

\section{Operational Definition}

A cutoff score of 12 and above on the 9-item Patient Health Questionnaire (PHQ-9) was considered having depression and otherwise, no depression. A cut of a summed score of 12 on the PHQ-9 screening instrument was recommended because of its higher specificity $(80.0 \%){ }^{24}$ The likelihood that a patient is falsely screened as depressed is then at an acceptable rate. Level of depression as mild, moderate, moderately severe, and severe depression was defined with a PHQ-9 score of 5-9, 10-14, 15-19, and 20-27, respectively. The same cutoff point was identified from studies conducted elsewhere. $^{17}$

Good glycemic control: Average fasting blood glucose level from three recent visits of $\leq 130 \mathrm{mg} / \mathrm{dL}$ was considered good glycemic control. Poor glycemic control: an average of three recent visits fasting blood glucose level of $>130 \mathrm{mg} / \mathrm{dL}$ was deemed to be poor glycemic control. ${ }^{7}$

Presence of hypertension: defined in the study as systolic BP level of $\geq 140 \mathrm{mmHg}$ and diastolic BP of $\geq 90$ $\mathrm{mmHg}$, or current treatment for hypertension with prescription medication. ${ }^{13,16}$

\section{Data Collection Method and Quality Control}

We collected data through face-to-face interviews and medical record review by four diploma holder data collectors who had previous experience in data collection in health surveys and knew the language and culture of surveyed people. Data collectors were closely supervised by two Health officers who were recruited for this purpose. The questionnaire was pretested before the actual data collection using 5\% (21) of the sample on a similar setting outside the study area. Findings and experiences from the pre-test were utilized to modify the tool.

\section{Analysis and Statistics}

Completeness of questionnaires was checked daily during the data collection period. Data were coded and entered into EpiData Entry software (version 3.1, EpiData Association, 
Odense, Denmark) and analyzed by using SPSS statistical software version 25 (SPSS Inc., Chicago, IL, USA). Descriptive statistics of the data, including frequencies, proportions, mean, standard deviation and cross-tabulations were used to summarize respondents' background characteristics. Bivariate and multivariable logistic regression were employed; any variable in bivariate analysis with a $p$-value $<0.25$ was put into a multivariate model to adjust for confounders. Significant associations with the outcome variable during multivariable analysis were identified on the basis of adjusted odds ratio (AOR) with $95 \%$ confidence interval (CI). Levels of significance were set at $5 \%(p$-value $<0.05)$.

\section{Ethical Consideration}

This study was approved by Wolaita Sodo University, College of Health Science and Medicine Ethical Review Committee (CHSM/ERC/107) and ethical clearance was obtained from the same office. The study was conducted in accordance with the Declaration of Helsinki. Support letter was written to the respective district health bureau explaining the objectives of the research and its significance so that medical director Halaba Kulito Hospital was contacted and requested for permission to conduct the survey. Participants were informed about the purpose, benefit, risk, confidentiality of the information and the voluntary nature of participation in the study. We obtained informed written consent. Participants were informed that they had the right to withdraw from the study at any time.

\section{Result}

\section{Socio-Demographic Characteristics}

Out of 418 sampled type-2 diabetic patients, a total of 410 were interviewed making a response rate of $98.1 \%$. The mean age of the respondents was 47.4 years, with a standard deviation of \pm 9.6 years. The majority of participants were married $264(64.4 \%)$ followed by widowed 73 (17.8\%). Little more than one fourth $(28.5 \%)$ of study participants had no formal education, while 71 (17.3\%) have attended at least elementary (grade 1-8) education (Table 1).

\section{Clinical and Self-Care Characteristics}

Among 410 study participants, it was found that majority 335 (81.7\%) and 233 (56.8\%) never had smoking and alcohol consumption history, respectively. Further, more than half (53.2\%) of participant reported regular physical activity. About two hundred sixty-one (63.7\%) and little more than two in three (67.8) study participants reported less than or equal to eight years of duration of diagnosis and treatment of
Table I Sociodemographic Characteristics of Type 2 Diabetic Patients at Halaba Kulito Hospital, South Ethiopia; 2019 ( $n=410)$

\begin{tabular}{|c|c|c|}
\hline \multirow[t]{2}{*}{ Characteristics } & \multicolumn{2}{|l|}{ Depression } \\
\hline & $\begin{array}{l}\text { No Frequency } \\
\text { (\%) }\end{array}$ & $\begin{array}{l}\text { Yes Frequency } \\
\text { (\%) }\end{array}$ \\
\hline Total & $290(70.7)$ & $120(29.3)$ \\
\hline \multicolumn{3}{|l|}{ Age } \\
\hline$<30$ & $5(50.0)$ & $5(50.0)$ \\
\hline $30-39$ & $65(77.4)$ & $19(22.6)$ \\
\hline $40-49$ & $102(69.9)$ & $44(30.1)$ \\
\hline $50-59$ & $75(72.5)$ & $28(27.2)$ \\
\hline$\geq 60$ & $43(64.2)$ & $24(35.8)$ \\
\hline \multicolumn{3}{|l|}{ Sex } \\
\hline Male & I42 (7I.0) & $58(29.0)$ \\
\hline Female & I $48(70.5)$ & $62(29.5)$ \\
\hline \multicolumn{3}{|l|}{ Residence } \\
\hline Urban & $165(69.6)$ & $72(30.4)$ \\
\hline Rural & $125(72.3)$ & $48(27.7)$ \\
\hline \multicolumn{3}{|l|}{ Marital status } \\
\hline Married & $195(73.9)$ & $69(36.1)$ \\
\hline Widowed & $47(64.4)$ & $26(35.6)$ \\
\hline Divorced & $27(65.9)$ & $14(34.1)$ \\
\hline Single & $21(65.9)$ & II (34.4) \\
\hline \multicolumn{3}{|l|}{ Educational status } \\
\hline No formal education & $74(63.2)$ & $43(36.8)$ \\
\hline Read and write & $72(76.6)$ & $22(23.4)$ \\
\hline Elementary (Grade I-8) & $57(80.3)$ & $14(19.7)$ \\
\hline High school (Grade 9-12) & $29(61.7)$ & $18(38.3)$ \\
\hline College and above & $58(71.6)$ & $23(28.4)$ \\
\hline \multicolumn{3}{|l|}{ Occupational status } \\
\hline Farmer & $113(67.7)$ & $54(32.3)$ \\
\hline Employed & $92(77.3)$ & $27(22.7)$ \\
\hline Self-employed & $27(7 \mid . I)$ & II (28.9) \\
\hline Merchant & $58(67.4)$ & $28(32.6)$ \\
\hline \multicolumn{3}{|l|}{ Had a child } \\
\hline Yes & $233(77.4)$ & $68(22.6)$ \\
\hline No & $57(52.3)$ & $52(47.7)$ \\
\hline \multicolumn{3}{|l|}{$\begin{array}{l}\text { Monthly income } \\
\text { (Ethiopian birr) }\end{array}$} \\
\hline$<500$ & $65(75.6)$ & $21(24.4)$ \\
\hline $50 \mathrm{I}-1200$ & $108(72.5)$ & $4 \mid(27.5)$ \\
\hline$|20|-2|5|$ & 69 (62.7) & 41 (37.3) \\
\hline$>2151$ & $48(73.8)$ & $17(26.2)$ \\
\hline
\end{tabular}

DM, respectively. Little less than one quarter (30.2\%) of study participants were hypertensive with the median systolic blood pressure $140(120-150) \mathrm{mmHg}$ and diastolic blood pressure 84 (78-89) $\mathrm{mmHg}$ (Table 2). 
Table 2 Clinical and Self-Care Characteristics of Type 2 Diabetic Patients at Halaba Kulito General Hospital, Halaba Kulito Town, Southern Ethiopia; $2019(n=410)$

\begin{tabular}{|c|c|c|}
\hline \multirow[t]{2}{*}{ Characteristics } & \multicolumn{2}{|l|}{ Depression } \\
\hline & No Frequency (\%) & Yes Frequency (\%) \\
\hline Total & $290(70.7)$ & $120(29.3)$ \\
\hline $\begin{array}{l}\text { Smoking status } \\
\text { Never } \\
\text { Current } \\
\text { Previous }\end{array}$ & $\begin{array}{l}245(73.1) \\
10(52.6) \\
35(62.5)\end{array}$ & $\begin{array}{l}90(26.9) \\
9(47.4) \\
21(37.5)\end{array}$ \\
\hline $\begin{array}{l}\text { Alcohol } \\
\text { consumption } \\
\text { Does not drink } \\
\text { Occasional } \\
\text { Always }\end{array}$ & $\begin{array}{l}175(75.1) \\
96(64.4) \\
19(67.9)\end{array}$ & $\begin{array}{l}58(24.9) \\
53(35.6) \\
9(32.1)\end{array}$ \\
\hline $\begin{array}{l}\text { Family history of } \\
\text { DM } \\
\text { No } \\
\text { Yes }\end{array}$ & $\begin{array}{l}97(65.5) \\
193(73.7)\end{array}$ & $\begin{array}{l}51(34.5) \\
69(26.3)\end{array}$ \\
\hline $\begin{array}{l}\text { Personal history of } \\
\text { depression } \\
\text { No } \\
\text { Yes }\end{array}$ & $\begin{array}{l}231(71.3) \\
59(68.6)\end{array}$ & $\begin{array}{l}93(28.7) \\
27(31.4)\end{array}$ \\
\hline $\begin{array}{l}\text { Hypertension } \\
\text { No } \\
\text { Yes }\end{array}$ & $\begin{array}{l}232(81.1) \\
58(46.8)\end{array}$ & $\begin{array}{l}54(18.9) \\
66(53.2)\end{array}$ \\
\hline $\begin{array}{l}\text { Systolic blood } \\
\text { pressure (mmHg) } \\
<120 \\
120-139 \\
140-159 \\
\geq 160\end{array}$ & $\begin{array}{l}131(74.4) \\
87(74.4) \\
53(61.6) \\
19(61.3)\end{array}$ & $\begin{array}{l}45(25.6) \\
30(25.6) \\
33(38.4) \\
12(38.7)\end{array}$ \\
\hline $\begin{array}{l}\text { Diastolic blood } \\
\text { pressure }(\mathbf{m m H g}) \\
\quad<80 \\
80-89 \\
90-99 \\
\geq 100\end{array}$ & $\begin{array}{l}139(75.1) \\
83(81.4) \\
47(63.5) \\
21(42.9)\end{array}$ & $\begin{array}{l}46(24.9) \\
19(18.6) \\
27(36.5) \\
28(57.1)\end{array}$ \\
\hline $\begin{array}{l}\text { Neuropathy } \\
\text { No } \\
\text { Yes }\end{array}$ & $\begin{array}{l}279(70.5) \\
1 I(78.6)\end{array}$ & $\begin{array}{l}117(29.5) \\
3(21.4)\end{array}$ \\
\hline $\begin{array}{l}\text { Nephropathy } \\
\text { No } \\
\text { Yes }\end{array}$ & $\begin{array}{l}283(70.9) \\
7(63.6)\end{array}$ & $\begin{array}{l}\text { II } 6(29.1) \\
4(36.4)\end{array}$ \\
\hline $\begin{array}{l}\text { Retinopathy } \\
\text { No } \\
\text { Yes }\end{array}$ & $\begin{array}{l}274(71.9) \\
16(55.2)\end{array}$ & $\begin{array}{l}107(28.1) \\
13(44.8)\end{array}$ \\
\hline
\end{tabular}

(Continued)
Table 2 (Continued).

\begin{tabular}{|c|c|c|}
\hline \multirow[t]{2}{*}{ Characteristics } & \multicolumn{2}{|l|}{ Depression } \\
\hline & No Frequency (\%) & Yes Frequency (\%) \\
\hline \multicolumn{3}{|l|}{ Disability } \\
\hline No & $283(70.8)$ & $117(29.3)$ \\
\hline Yes & $7(70.0)$ & $3(30.0)$ \\
\hline \multicolumn{3}{|l|}{$\begin{array}{l}\text { Duration of DM } \\
\text { diagnosis (Years) }\end{array}$} \\
\hline$\leq 8$ & $193(73.9)$ & $68(26.1)$ \\
\hline $9-16$ & $70(64.8)$ & $38(35.2)$ \\
\hline$\geq 17$ & $27(65.9)$ & $14(34.1)$ \\
\hline \multicolumn{3}{|l|}{$\begin{array}{l}\text { Duration of DM } \\
\text { treatment (Years) }\end{array}$} \\
\hline$\leq 8$ & $207(74.5)$ & 7I (25.5) \\
\hline $9-16$ & $64(64.6)$ & $35(35.4)$ \\
\hline$\geq 17$ & $19(57.6)$ & $14(42.4)$ \\
\hline \multicolumn{3}{|l|}{ Glycemic control } \\
\hline Good ( $\leq 126 \mathrm{mg} / \mathrm{dL})$ & $216(84.0)$ & $4 \mid(16.0)$ \\
\hline Poor $(\geq 127 \mathrm{mg} / \mathrm{dL})$ & $74(48.4)$ & $79(51.6)$ \\
\hline \multicolumn{3}{|l|}{$\begin{array}{l}\text { Diabetes } \\
\text { treatment regime }\end{array}$} \\
\hline Insulin only & $119(70.0)$ & $51(30.0)$ \\
\hline $\begin{array}{l}\text { Oral hypoglycemic } \\
\text { and insulin }\end{array}$ & 70 (72.9) & $26(27.1)$ \\
\hline $\begin{array}{l}\text { Oral hypoglycemic } \\
\text { agent only }\end{array}$ & $101(70.1)$ & $43(29.9)$ \\
\hline
\end{tabular}

\section{Prevalence of Untreated Depression}

As stated elsewhere in this document, the prevalence of depression among T2DM patients was computed using a 9-item PHQ questionnaire. Accordingly, one hundred twenty $(29.3 \%$ with $95 \%$ CI: $25.0,34.0)$ study participants were identified as having depressive episode in the two weeks preceding the survey. The largest percentage of participants manifested the symptoms of mild depression $(\mathrm{PHQ}=5-9)(50.0 \%)$ (Figure 1).

\section{Factors Associated with Untreated Depression}

In bivariate analysis, nine variables including marital status, smoking status, glycemic control, having hypertension, duration of DM diagnosis, duration of DM treatment, having a child, developing retinopathy and family history of DM were significant and fitted for multivariable regression with $\mathrm{p}$-value $<0.25$ (Table 3 ). The multivariate model showed that three explanatory variables significantly associated with untreated depression 


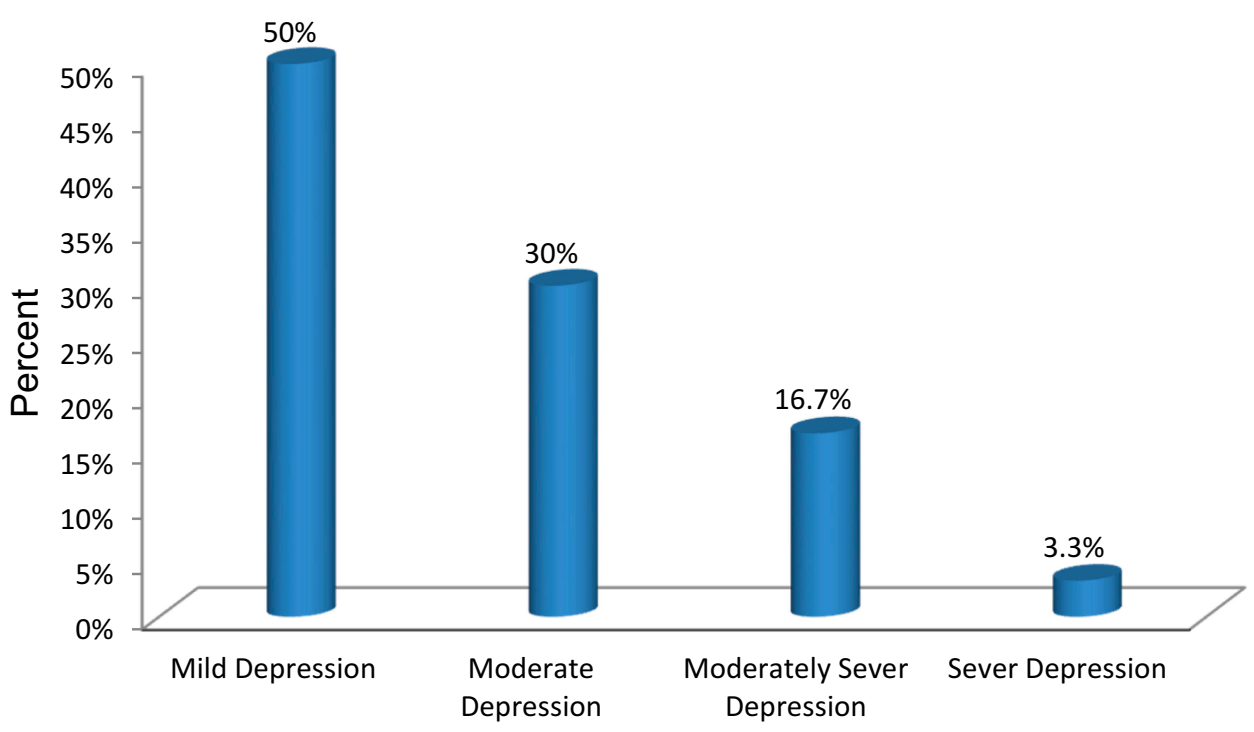

Figure I Severity of untreated depression among type 2 diabetic patients attending Halaba Kulito general hospital diabetic clinic, Southern Ethiopia, 2019.

among type 2 diabetic patients. Being hypertensive was 5.6 times $(\mathrm{AOR}=5.66 ; 95 \% \mathrm{CI}: 3.24,9.86)$ more likely to be depressed than their counterparts. Participants who had no child were 3.3 times ( $\mathrm{AOR}=3.32 ; 95 \% \mathrm{CI}: 1.88,5.86$ ) more likely to develop depression than those who responded no child. Moreover, glycemic control among type 2 diabetic patients had a significant association with depression by which; the odds of untreated depression among T2DM who had poor glycemic control were more than 6 times $(\mathrm{AOR}=6.23 ; 95 \% \mathrm{CI}: 3.65,10.54)$ higher than those who had good glycemic control (Table 3).

\section{Discussion}

\section{Magnitude of Depression}

This cross-sectional study provides systematically collected data to assess the magnitude and associated factor of diabetic depression among type 2 diabetic patients. Accordingly, the magnitude of depression among T2DM patients was $29.3 \%$. Comparable findings in the magnitude of depression were reported from similar studies conducted in Ghana $(31.3 \%)^{14}$ and Kedah, Malaysia (32.1\%). ${ }^{25}$

Again, the magnitude of depression in our study is higher than similar reports from Addis Ababa and Mekele town, Ethiopia (13\% and 17, respectively), ${ }^{26,27}$ Malaysia $(15.7 \%)^{28}$ and community-based cross-sectional studies using the Beck Depression Inventory scale conducted in Nepal $(22.7 \%)^{1}$ and Brazil (18.6\%). ${ }^{29}$ The difference might be attributed to the difference in socio-economic background, study period and using a different assessment tool with varying specificity and sensitivity scale to detect the outcome variable. ${ }^{1,27,29}$ For instance, a study conducted in Brazil uses psychiatrist to interview a relatively small sample (70) of aged 30-65 years type 2 diabetic outpatients. Likewise, a prospective cohort study conducted in Madrid, Spain shows a depression prevalence of $20 \%$. The possible reason for the observed difference in finding might be due to the assumption that in the study conducted in Madrid, Spain, the authors used age-appropriate depression screening measures collected by the general practitioners under routine clinical practice and this might possibly lower the prevalence. Our study finding is smaller than study reports conducted at Addis Ababa, Ethiopia (44.7\%), ${ }^{22}$ Saudi Arabia $(49.6 \%),{ }^{30}$ Karachi, Pakistan (43.5\%) ${ }^{10}$ Malaysia (40.3\%), ${ }^{15}$ Nepal $(40.3 \%)^{31}$ and Montenegro $(62.9 \%) .{ }^{17}$ This may partly be due to the difference in socio-demographic characteristics, ${ }^{30}$ small sample size, ${ }^{2,14}$ study period and outcome variable measurement methods ${ }^{10,15,30,31}$ of study subjects.

\section{Factors Significantly Associated with Depression}

After controlling the effect of confounding variable, poor glycemic control, having a child and having hypertension were significantly associated with the outcome variable.

From this study, it was found that poor glycemic control is one of the variables significantly associated with depression. Participants who have poor glycemic control were about 6 times more likely to develop depression than those who have good glycemic control. Several studies admitted that diabetic patients with poor glycemic control 
Table 3 Bivariate and Multivariable Analysis of Factors Associated with Untreated Depression Among Type 2 Diabetic Patients Attending Halaba Kulito General Hospital Diabetic Clinic, Southern Ethiopia, 2019 ( $n=410)$

\begin{tabular}{|c|c|c|c|c|}
\hline \multirow[t]{2}{*}{ Characteristics } & \multicolumn{2}{|c|}{ Depression } & \multirow[t]{2}{*}{$\operatorname{COR}^{a}(95 \% \mathrm{Cl})$} & \multirow[t]{2}{*}{ AOR $(95 \% \mathrm{Cl})$} \\
\hline & No (\%) & Yes (\%) & & \\
\hline \multicolumn{5}{|l|}{ Marital status } \\
\hline Married & 195 (73.9) & $69(26.1)$ & 1 & 1 \\
\hline Widowed & $47(64.4)$ & $26(35.6)$ & $\mathrm{I} .56(0.90,2.7 \mathrm{I})$ & $0.87(0.05, \mid 4.80)$ \\
\hline Divorced & $27(65.9)$ & $14(34.1)$ & $1.46(0.72,2.95)$ & $0.32(0.10,5.78)$ \\
\hline Single & $21(65.6)$ & II (34.4) & $1.48(0.67,3.22)$ & $0.51(0.02,9.53)$ \\
\hline \multicolumn{5}{|l|}{ Had child } \\
\hline Yes & $233(77.4)$ & $68(22.6)$ & 1 & $\mathrm{I}$ \\
\hline No & $57(52.3)$ & $52(47.7)$ & $3.12(1.96,4.96)$ & $3.32(1.88,5.86)^{*}$ \\
\hline \multicolumn{5}{|l|}{ Smoking } \\
\hline Never & $245(73.1)$ & $90(26.9)$ & 1 & 1 \\
\hline Current & $10(52.6)$ & $9(47.4)$ & $2.45(0.96,6.22)$ & $2.39(0.69,8.19)$ \\
\hline Previous & $35(62.5)$ & $21(37.5)$ & $1.63(0.90,2.95)$ & $\mathrm{I} .64(0.8 \mathrm{I}, 3.32)$ \\
\hline \multicolumn{5}{|c|}{ Glycemic control } \\
\hline Good & $216(84.0)$ & $4 I(16.0)$ & 1 & 1 \\
\hline Poor & $74(48.4)$ & $79(51.6)$ & $5.62(3.54,8.91)$ & $6.23(3.65,10.54)^{*}$ \\
\hline \multicolumn{5}{|c|}{ Having hypertension } \\
\hline No & $232(8 I .1)$ & $54(18.9)$ & 1 & 1 \\
\hline Yes & $58(46.8)$ & $66(53.2)$ & $4.88(3.08,7.74)$ & $5.66(3.24,9.86)^{*}$ \\
\hline \multicolumn{5}{|l|}{ Retinopathy } \\
\hline No & 274 (7I.9) & $107(28.1)$ & 1 & 1 \\
\hline Yes & $16(55.2)$ & $13(44.8)$ & $2.08(0.96,4.47)$ & $2.13(0.81,5.59)$ \\
\hline \multicolumn{5}{|l|}{ Duration of DM } \\
\hline$\leq 8$ & $193(73.9)$ & $68(26.1)$ & 1 & 1 \\
\hline $9-16$ & $70(64.8)$ & $38(35.2)$ & $1.54(0.95,2.49)$ & $0.83(0.03,18.34)$ \\
\hline$\geq 17$ & $27(65.9)$ & $14(34.1)$ & $1.47(0.72,2.97)$ & $0.41(0.07,2.28)$ \\
\hline \multicolumn{5}{|c|}{ Duration of DM treatment (Years) } \\
\hline$\leq 8$ & $207(74.5)$ & $7 \mid(25.5)$ & 1 & 1 \\
\hline $9-16$ & $64(64.6)$ & $35(35.4)$ & $1.59(0.97,2.60)$ & $2.50(0.65,9.60)$ \\
\hline$\geq 17$ & $19(57.6)$ & $14(42.4)$ & $2.14(1.02,4.50)$ & $4.46(0.75,26.32)$ \\
\hline \multicolumn{5}{|c|}{ Family history of DM } \\
\hline No & $97(65.5)$ & $5 \mathrm{I}(34.5)$ & $\mathrm{I} .47(0.95,2.27)$ & $\mathrm{I} .34(0.78,2.30)$ \\
\hline Yes & $193(73.7)$ & $69(26.3)$ & 1 & 1 \\
\hline
\end{tabular}

Notes: $*$ Significant association at $\mathrm{p}$-value $<0.05$. ${ }^{\text {a }}$ Crude odds ratio.

have a significant association with depression. ${ }^{7,30,32}$ As explained elsewhere, ${ }^{12,16}$ poor glycemic control can be associated with poor medication adherence and poor quality of life including the absence of dietary plans and physical activity which may increase the risk of developing more significant stress, worsening of mood and less life satisfaction.

In our study, having hypertension was shown to be associated with depression. Having hypertension increased
5.5 times the likelihood of depression among T2DM patients. Similarly, having hypertension has been identified as a significant factor for depression in studies conducted in Pakistan ${ }^{33}$ and India. ${ }^{13}$ Moreover, a community-based cross-sectional study conducted in Duhabi-Bhaluwa, Nepal revealed that having an additional illness increases the likelihood of developing major depressive disorder among people with T2DM. ${ }^{1}$ These findings reflect the fact that having hypertension is seen to be an obvious 
burden to the existing illness. Further, depression among type 2 diabetic patients was found to be strongly associated among those who had no child. This result was supported by the study conducted in Kedah, Malaysia ${ }^{25}$ in which type 2 diabetic patients who live with their children were significantly less depressed when compared with those who live alone. A plausible explanation could be the social stigma associated with being childless which may lead to some social and psychological problems.

\section{Study Limitation and Strength}

Although the current study provided much useful information, it has some limitations to be noted that can be subsequently addressed by other studies. Our study was limited to a single but significant healthcare center in Halaba town, and therefore, the result of this study may not necessarily be generalizable to other populations. Since we did not conduct sensitivity analysis, the choice we made on analysis modeling might have potential bias and the results across different models may or may not be consistent. In addition, the crosssectional design of the study limits our ability to make causal inferences, and therefore, the findings of this study must be interpreted with caution.

\section{Conclusion}

The findings of this study indicate depression is a common mental health problem among type 2 diabetic patients which is related to being hypertensive, having no child and poor glycemic control. This emphasizes for much need interventions, including strong medication adherence and self-care activities such as exercise or healthful diet for optimal glycemic control. Furthermore, tools such as the Patient Health Questionnaire-9 and the Beck Depression Inventory may be incorporated into the beginning of a clinic visit so that responses indicating severe levels of depressive symptoms can be further assessed and addressed promptly and directly with the patient.

\section{Abbreviations}

DM, diabetes mellitus; PHQ-9, Patient Health Questionnaire9; T2DM, type 2 diabetes mellitus.

\section{Data Sharing Statement}

All data are already described and included in the manuscript.

\section{Ethics Approval and Informed Consent}

College of Health Science and Medicine Ethical Review Committee (CHSM/ERC/107) of Wolaita Sodo University provided ethical clearance. Official letter of permission was obtained from the same office. The study was conducted in accordance with the Declaration of Helsinki. Support letter was written to the respective district health bureau. Participants were informed about the purpose, benefit, risk, confidentiality of the information and the voluntary nature of participation in the study. Informed written consent was obtained.

\section{Acknowledgments}

The authors would like to acknowledge Wolaita Sodo University for providing us financial support to undertake this study.

\section{Author Contributions}

All authors made substantial contributions to conception and design, data analysis, drafting or revising the article; took part in drafting the article, gave final approval of the version to be published, and agree to be accountable for all aspects of the work.

\section{Funding}

Wolaita Sodo University has funded this work for data collection. Academic and Research Directorate Office of College of Health Sciences, Wolaita Sodo University, was involved in the project through monitoring and evaluation of the work. The funder had no role in study design, data collection and analysis, interpretation of the data, the decision to publish, or preparation of the manuscript.

\section{Disclosure}

The authors declare that they have no competing interest.

\section{References}

1. Avimash KS, Khanal VK, Sah RB, Ghimire A. Depression among people living with type 2 diabetes in an urbanizing community of Nepal. PLoS One. 2019;14:1-11.

2. Kilonzo SB, Gunda DW, Bakshi FA, Kalokola F, Mayala HA, Dadi H. Control of hypertension among diabetic patients in a referral hospital in Tanzania: a cross-sectional study. Ethiop J Health Sci. 2017;27 (5):473-480. doi:10.4314/ejhs.v27i5.5

3. Abejew AA, Belay AZ, Kerie MW. Diabetic complications among adult diabetic patients of a tertiary hospital in northeast Ethiopia. Adv Public Health. 2015;2015:1-7. doi:10.1155/2015/290920

4. Korsa AT, Genemo ES, Bayisa HG, Dedefo MG. Diabetes mellitus complications and associated factors among adult diabetic patients in selected hospitals of west Ethiopia. Open Cardiovasc Med J. 2019;13 (1):41-48. doi:10.2174/1874192401913010041 
5. Abebe N, Kebede T, Addise D. Diabetes in Ethiopia 2000-2016prevalence and related acute and chronic complications; a systematic review. Afr J Diabetes Med. 2017;25(2):7-12.

6. Engidaw NA, Wubetu AD, Basha EA. Prevalence of depression and its associated factors among patients with diabetes mellitus at Tirunesh-Beijing general hospital, Addis Ababa, Ethiopia. BMC Public Health. 2020;20(1):266. doi:10.1186/s12889-020-8360-2

7. AL Mouaalamy NA. Prevalence of depression among type 2 diabetic patients attending diabetic clinic at primary health care centers in Jeddah, Saudi Arabia. Arch Med. 2018;10(5:1):1-7.

8. Ali S, Stone MA, Peters JL, Davies MJ, Khunti K. The prevalence of co-morbid depression in adults with Type 2 diabetes: a systematic review and meta-analysis. Diabet Med. 2006;23(11):1165-1173. doi:10.1111/j.1464-5491.2006.01943.x

9. Birhanu AM, Alemu FM, Ashenafie TD, et al. Depression in diabetic patients attending University of Gondar Hospital Diabetic Clinic, Northwest Ethiopia. Diabetes Metab Syndr Obes Targets Ther. 2016;9:155-162.

10. Khan ZD, Lutale J, Moledina SM. Prevalence of depression and associated factors among diabetic patients in an outpatient diabetes clinic. Psychiatry J. 2019;2019:1-6. doi:10.1155/2019/2083196

11. Sweileh WM, Abu-Hadeed HM, Al-Jabi SW, Zyoud SH. Prevalence of depression among people with type 2 diabetes mellitus: a cross sectional study in Palestine. BMC Public Health. 2014;14(1):163. doi: 10.1186/1471-2458-14-163

12. Darwish L, Beroncal E, Sison MV, Swardfager W. Depression in people with type 2 diabetes: current perspectives. Diabetes Metab Syndr Obes. 2018;11:333-343. doi:10.2147/DMSO.S106797

13. Paulraj S, Rajasekaran S, Mathew AC. Prevalence of depression and it's associated factors in adults with diabetes mellitus: a cross-sectional study in a tertiary care centre. Adv Med Sci An Int J. 2017;4(1):1-9.

14. Akpalu J, Yorke E, Ainuson-Quampah J, Balogun W, Yeboah K. Depression and glycaemic control among type 2 diabetes patients: a cross-sectional study in a tertiary healthcare facility in Ghana. BMC Psychiatry. 2018;18(1):357. doi:10.1186/s12888-018-1933-2

15. Ganasegeran K, Renganathan P, Manaf RA, Al-Dubai SA. Factors associated with anxiety and depression among type 2 diabetes outpatients in Malaysia: a descriptive cross-sectional single-centre study. BMJ Open. 2014;4(4):e004794. doi:10.1136/bmjopen-2014-004794

16. Salinero-Fort MA, Gómez-Campelo P, San Andrés-Rebollo FJ, et al. Prevalence of depression in patients with type 2 diabetes mellitus in Spain (the DIADEMA Study): results from the MADIABETES cohort. BMJ Open. 2018;8(9):e020768. doi:10.1136/bmjopen-2017-020768

17. Šabanović A, Maksimović N, Stojanović-Tasić M, Bakić M, Grgurević A. Factors associated with depression in the patients with diabetes mellitus type 2. Vojnosanit Pregl. 2019;76(11):1178-1183. doi:10.2298/VSP170328029S

18. Tesfaye T, Shikur B, Shimels T, Firdu N. Prevalence and factors associated with diabetes mellitus and impaired fasting glucose level among members of federal police commission residing in Addis Ababa, Ethiopia. BMC Endocr Disord. 2016;16(1):68. doi:10.1186/ s12902-016-0150-6

19. Tiki T. Prevalence and associated factors of depression among type 2 diabetes mellitus patients on follow up at ambo general hospital, Oromia regional state, Ethiopia, Institutional Based Cross Sectional Study. J Depress Anxiety. 2017;6(01):1044-2167.
20. Wordofa BP Prevalence of Depression and Associated Factors among Adult Diabetic Patients Attending Outpatient Department, at Felege Hiwot Referral Hospital, Bahir Dar, Northwest Ethiopia [Doctoral dissertation, Addis Ababa University]; 2016

21. United Nations, Department of Economic and Social Affairs, Population Division. World population prospects: the 2017 revision; 2017. Available from: https://www.un.org/development/desa/publica tions/world-population-prospects-the-2017-revision.htm. Accessed March 20, 2020.

22. Habtewold TD, Alemu SM, Haile YG. Sociodemographic, clinical, and psychosocial factors associated with depression among type 2 diabetic outpatients in Black Lion General Specialized Hospital, Addis Ababa, Ethiopia: a cross-sectional study. BMC Psychiatry. 2016;16(103). doi:10.1186/s12888-016-0809-6

23. Lin EH, Katon W, Von Korff M, et al. Relationship of depression and diabetes self-care, medication adherence, and preventive care. Diabetes Care. 2004;27(9):2154-2160. doi:10.2337/diacare.27.9. 2154

24. van Steenbergen-weijenburg KM, de Vroege L, Ploeger RR, et al. Validation of the PHQ-9 as a screening instrument for depression in diabetes patients in specialized outpatient clinics. BMC Health Serv Res. 2010;10:235. doi:10.1186/1472-6963-10-235

25. Azniza MR, Draman N, Siti Suhaila MY, Muhamad R. Depression and potential risk factors among the elderly with Type 2 Diabetes Mellitus in Kedah, Malaysia. Med J Malaysia. 2019;74(2):103-108.

26. Dejenie Habtewold T, Radie YT, Sharew NT. Prevalence of depression among type 2 diabetic outpatients in Black Lion general specialized hospital, Addis Ababa, Ethiopia. Depress Res Treat. 2015;2015:184902. doi:10.1155/2015/184902

27. Mossie TB, Berhe GH, Kahsay GH, Tareke M. Prevalence of depression and associated factors among diabetic patients at Mekelle City, North Ethiopia. Indian $J$ Psychol Med. 2017;39(1):52-58. doi:10.4103/0253-7176.198947

28. Hashim NA, Ariaratnam S, Salleh MR, Said MA, Sulaiman AH. Depression and associated factors in patients with type 2 diabetes mellitus. East Asian Arch Psychiatry. 2016;26(2):77-82.

29. Papelbaum M, Moreira RO, Coutinho W, et al. Depression, glycemic control and type 2 diabetes. Diabetol Metab Syndr. 2011;3(1):26. doi:10.1186/1758-5996-3-26

30. El Mahalli AA. Prevalence and predictors of depression among type 2 diabetes mellitus outpatients in Eastern Province, Saudi Arabia. Int J Health Sci. 2015;9(2):119. doi:10.12816/0024105

31. Niraula K, Kohrt BA, Flora MS, et al. Prevalence of depression and associated risk factors among persons with type-2 diabetes mellitus without a prior psychiatric history: a cross-sectional study in clinical settings in urban Nepal. BMC Psychiatry. 2013;13(1):309. doi:10.1186/1471-244X-13-309

32. Gonzalez JS, Peyrot M, McCarl LA, et al. Depression and diabetes treatment nonadherence: a meta-analysis. Diabetes Care. 2008;31 (12):2398-2403. doi:10.2337/dc08-1341

33. Khuwaja AK, Lalani S, Dhanani R, Azam IS, Rafique G, White F. Anxiety and depression among outpatients with type 2 diabetes: a multi-centre study of prevalence and associated factors. Diabetol Metab Syndr. 2010;2(1):72. doi:10.1186/1758-5996-2-72 


\section{Publish your work in this journal}

Diabetes, Metabolic Syndrome and Obesity: Targets and Therapy is an international, peer-reviewed open-access journal committed to the rapid publication of the latest laboratory and clinical findings in the fields of diabetes, metabolic syndrome and obesity research. Original research, review, case reports, hypothesis formation, expert opinion and commentaries are all considered for publication. The manuscript management system is completely online and includes a very quick and fair peer-review system, which is all easy to use. Visit http://www.dovepress.com/testimonials.php to read real quotes from published authors.

Submit your manuscript here: https://www.dovepress.com/diabetes-metabolic-syndrome-and-obesity-targets-and-therapy-journal 